\title{
Economic Impact of New Biosafety Recommendations for Dental Clinical Practice During COVID-19 Pandemic
}

\author{
Yuri Wanderley Cavalcanti ${ }^{1}$, Rennis Oliveira da Silva ${ }^{1} @$, Leonardo de Freitas Ferreira ${ }^{1}$, Edson \\ Hilan Gomes de Lucena ${ }^{1}$, Andreza Maria Luzia Baldo de Souza ${ }^{2}$, Denise de Fátima Barros

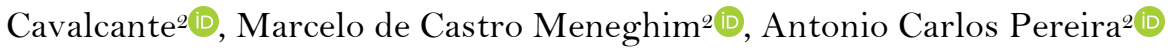

1Department of Clinical and Social Dentistry, School of Dentistry, Federal University of Paraiba, João Pessoa, PB, Brazil. ${ }^{2}$ Department of Community Dentistry, Piracicaba Dental School, University of Campinas, Campinas, SP, Brazil.

Author to whom correspondence should be addressed: Yuri Wanderley Cavalcanti, DDS, PhD, Clinical and Social Dentistry Department, Federal University of Paraiba, DCOS/CCS/UFPB, Cidade Universitária, Campus I, Joao Pessoa, PB, Brazil. 58035-070. Phone: +55 83999823170. E-mail: yuri@,ccs.ufpb.br.

Academic Editor: Ana Maria Gondim Valença

Received: 15 June 2020 / Accepted: 07 July 2020 / Published: 21 July 2020

\begin{tabular}{l} 
How to cite this article: Cavalcanti YC, Silva RO, Ferreira LF, Lucena EHG, Souza AMLB, Cavalcante DFB, et al. \\
Economic impact of new biosafety recommendations for dental clinical practice during COVID-19 pandemic. Pesqui Bras \\
Odontopediatria Clín Integr. 2020; 20(supp1):e0133. https://doi.org/10.1590/pboci.2020.143 \\
\hline
\end{tabular}

\begin{abstract}
COVID-19 pandemic implied new biosafety recommendations to avoid dissemination of SARS-CoV-2 virus within healthcare centers. Changes on recommended personal protective equipment (PPE), decontamination protocols and organization of patient demand resulted may result in cost variation. Based on this, the present study aimed to evaluate the economic impact of new biosafety recommendations for oral healthcare assistance during COVID-19. An Activity Based Costing evaluation was used to calculate the acquisition of PPE and decontamination solutions recommended for dental practice during COVID-19 pandemic in Brazil. PPE and decontamination solutions quantity and frequency of use were based on the newly COVID-19 recommendations. Costs (in Brazilian Real - $\mathrm{R} \$$ ) for biosafety recommendations pre- and post-COVID-19 were outlined and calculated for each patient, service shift and year. A sensitivity analysis considered $20 \%$ variation of direct costs. Previously to COVID-19 pandemic, direct costs of biosafety recommendations consisted of $\mathrm{R} \$ 0.84$ per patient, $\mathrm{R} \$ 6.69$ per service shift and $\mathrm{R} \$ 3,413.94$ per year. Post-COVID-19 costs of biosafety recommendations resulted in $\mathrm{R} \$ 16.01$ per patient, $\mathrm{R} \$ 128.07$ per service shift, and $\mathrm{R} \$ 32,657.96$ per year. Yearly costs can vary between $\mathrm{R} \$ 26,126.37$ and $\mathrm{R} \$ 39,189.56$. The annual budget increase necessary to adopt post-COVID biosafety recommendations was $\mathrm{R} \$ 29,244.02$. Newly biosafety recommendations increased significantly the costs of oral healthcare assistance during COVID-19 pandemic. Decision making of healthcare managers must consider rational and equity allocation of financial resources.
\end{abstract}

Keywords: Costs and Cost Analysis; Health Care Costs; Personal Protective Equipment; COVID-19. 


\section{Introduction}

New coronavirus (SARS-CoV-2) infection is associated with a serious and acute respiratory disease, which has rapidly spread around the world between the end of 2019 and the first quarter of 2020 [1,2]. The disease caused by SARS-CoV-2 became known as COVID-19 and was recognized by the World Health Organization as a global pandemic [3,4]. A rapid spread of COVID-19 has overcrowded hospital medical services and caused the collapse of health systems around the world [5].

COVID-19 pandemic has infected around 7.8 million people and caused 430 thousand deaths worldwide, by middle of June 2020 [6]. Besides life losses and health system collapse, fighting COVID-19 outbreak also implied economical challenges for many countries. Isolation, Quarantine, Social Distancing and Community Containment were drawn as protective measures to avoid COVID-19 spread and this have been causing a worldwide reduction of economical activity [7].

Nevertheless, people are still getting sick from other ordinary diseases and prevention within healthcare centers is more than necessary. Community-use of facemasks has been suggested as a protective measures for every people and changes within personal protection of healthcare professional have also been recommended [7-9].

Considering dental caries is one of most prevalent diseases worldwide [10] and dental pain demands urgent assistance [11], healthcare must be prepared to deal with dental urgency and emergency needs, even under a pandemic scenario [12]. In order to give proper assistance in the context of COVID-19 pandemic, it is necessary that dentists and healthcare centers adopt the use of level-2 or level-3 personal protective equipment (PPE), in addition to strategies for controlling aerosols [9].

Based on that, apart from regular PPE used by a dentist, new equipment and disinfection protocols are recommended for a safe practice within dental offices $[8,13,14]$. The incorporation of those newly recommended biosafety practices might impact significantly the costs of a dental consultation during the COVID-19 pandemic. Therefore, this study aimed to evaluate the economic impact of new biosafety recommendations for dental clinical practice during COVID-19, within the public oral healthcare sector.

\section{Material and Methods}

This study consisted on a partial economic evaluation in which the Activity Based Costing appraisal was used for calculating the acquisition of PPE and decontamination solutions recommended for dental clinical practice during COVID-19 pandemic in Brazil. The ABC is used for strategic cost analysis that affects an organization's resource consumption, by using a micro-costing technique with a bottom-up approach [15]. The methodology followed the practices recommended by CHEERS [16], REBRATS (Brazilian Health Technology Assessment Network) [17) and an internationally accepted recommendation [18].

This study adopted the perspective of the local public healthcare manager. Therefore, costs and scenarios were defined according the context of a public oral healthcare service. The direct cost estimates, including PPE and room cleaning supplies, involved three stages: identification; quantity; and cost of the resources consumed. The resources were identified and quantified in accordance with their use in the treatment, with monetary values being attributed.

The Microsoft Excel program was used to list the items needed for performing dental treatment. A panel of specialists composed of five experienced professionals aligned and standardized the technique for public oral healthcare. The estimated portions and times were based on the responses of the expert panel and on national sanitary agency recommendation [19]. There was no need to return to the experts (2nd review) to make a decision on the items surveyed. 
This study considered 2 scenarios: pre-COVID and post-COVID pandemic. For pre-COVID scenario, the following assumptions were defined: a total of 8 consultations per period of 4 working hours; 2019 pricing values extracted from the Health Price Bank of the Ministry of Health. A maximum of 4 consultations per period of 4 working hours were defined for post-COVID scenario $[8,13,14,18]$. Pricing values for post-COVID scenario were obtained from at least three online quotations made in May/2020.

Pre-COVID scenario considered the standard use of disposable gloves, disposable mask, disposable cap, disposable gown and protective goggles [14]. A pair of gloves is used for each patient, whilst mask, head cover and gown are used during the whole period of 4 working hours. Protective goggles were estimated for being used during the whole year by the dentist and oral health assistant, being disinfected between every patient. The costs of protective goggles were diluted for the number of uses. All other materials and equipment were considered disposable.

Post-COVID scenario considered the use of standard PPE and level-2 PPE. Post-COVID scenario recommends the use of disposable gloves, $\mathrm{N}_{5} / \mathrm{FFP} 2$ mask, disposable mask, disposable cap, disposable shoe cover, waterproof medical coat, disposable gown, protective goggles and face shield [8,14,19]. Every disposable item is switched after each patient within the post-COVID scenario. Since a disposable mask is used over a N95/FFP2 mask, this later is used for the whole working shift [19]. The waterproof medical coat was recommended to being used for the whole day. The use of protective goggles and face shield were recommended for the dentist and oral health assistant, being disinfected between every patient. The costs of protective goggles and face shield were diluted for the number of uses; and those equipment were recommended to be switched every six months.

First step detailed necessary PPE. For this purpose, the micro-costing technique was used, where the inputs were attributed to the treatment, according to the quantity spent. In addition, the values of specific PPE were diluted according to their useful life, taking into consideration the values suggested by the manufacturers and panel of specialists. Long-term use equipment had their costs diluted for one year. Long-term use equipment consisted of protective goggles, face shield, Infrared Thermometer, Oximeter and Sanitizing carpet. The second step consisted of consulting the most assertive sources of information to obtain a realistic and unique national value for each item. In this step, web search involved two websites: the Health Price Bank (http://portalms.saude.gov.br/gestao-do-sus/economia-da-saude/banco-de-precos-em-saude) and the Price Panel from Ministry of Economy (https://paineldeprecos.planejamento.gov.br/). These websites present summary of prices derived from bids for material acquisition throughout Brazil. Additionally, current online quotation (May/2020) was obtained from widely used websites for professional dental products.

Costs were adjusted according to the number of PPE items used per consultation, as well as for diluted costs for permanent long-term use items (i.e.: face shield). Costs (in Brazilian Reais - R $\$$ ) for biosafety recommendations pre- and post-COVID-19 pandemic were outlined and calculated for each patient, service shift $(4 \mathrm{~h})$ and year. A whole year consisted of 255 working days.

No discounts and corrections for inflation were used because this economical evaluation considered the 2020 scenario. This study did not aim to estimate costs for a longer period, since it is expected costs may vary according the progress of COVID-19 pandemic. Nevertheless, a sensitivity analysis was carried out in the two scenarios (pre and post-COVID). Pre-COVID scenario considered $20 \%$ variation. For post-COVID scenario, some items have experienced exponential price rise due to increased demand and speculation. The following items were subjected to $20 \%$ variation: gloves, N95/FFP2 mask, disposable mask, disposable cap, waterproof medical coat and fenestrated surgical field. 


\section{Results}

Table 1 shows the pre-COVID values, in which daily practice required a low amount of PPE and products for personal hygiene and cleaning of the dental office. Previously to COVID-19 pandemic, direct costs of biosafety recommendations consisted of $\mathrm{R} \$ 0.84$ per patient, $\mathrm{R} \$ 6.69$ per service shift and $\mathrm{R} \$ 3,413.94$ per year (from $\mathrm{R} \$ 2,731.16$ to $\mathrm{R} \$ 4,096.73$ ) (Table 1).

The values shown in Table 2 illustrate the scenario post-COVID, in which new PPE, equipment and cleansing solutions were added to the scenario. Post-COVID costs of biosafety recommendations resulted in $\mathrm{R} \$ 16.01$ per patient, $\mathrm{R} \$ 128.07$ per service shift, and $\mathrm{R} \$ 32,657.96$ per year (costs can vary from $\mathrm{R} \$ 26,126.37$ to $\mathrm{R} \$ 39,189.56$ ). Costs of disposable PPE within post-COVID scenario consisted of $\mathrm{R} \$ 122$ (equivalent to $95.26 \%$ of the total).

The annual budget increase necessary to adopt the biosafety recommendations in dental healthcare post-COVID-19, was $\mathrm{R} \$ 29,244.02$. According to sensitivity analysis, this impact ranged from $\mathrm{R} \$ 23,395.21$ (more optimistic) to $\mathrm{R} \$ 35,092.82$ (more pessimistic).

\section{Discussion}

Results from this study shows that changes in biosafety protocols during COVID-19 pandemic increased significantly the costs of dental consultations. It was observed that costs for a unique dental consultation increased 19.05 times, based on changes between pre- and post-COVID protocols. Yearly cost of oral healthcare assistance increased 9.5 times. The increase in the number of PPE explains the increase in the price per period and, consequently, greater impact on the budget. The costs of disposable PPE within the postCOVID scenario consisted of $95.26 \%$ of the total and this is due the impossibility of PPE re-use between patients. Regardless the rise of PPE values, the post-COVID scenario imposed an increase in the number of PPE to be used. The purchase of new equipment such as a thermometer or oximeter is optional. However, they are of great importance for triage of the COVID-19 symptoms. Changes on biosafety recommendations within the dental practice may persist until a vaccine can be obtained and active circulation of the virus decrease.

COVID-19 pandemic has seriously modified the dynamics of healthcare provision worldwide $[5,8,13,14]$. In addition to the health and sanitary crisis, COVID-19 outbreak resulted in new biosafety protocols and novel routine of healthcare services. Such "new normal" scenario is characterized by extensive use of telemedicine, flexible deployment of the workforce, rationale use of triage, and outmost concerns to biosafety [20]. Nevertheless, assistance to urgent and emergency dental needs is still frequent and necessary. In a short period of time, elective health procedures will also be resumed [20]. Based on that, it is urgent to discuss the economical impact of new biosafety recommendations to dental care assistance during COVID-19 pandemic.

The results form this study considered the perspective of public oral healthcare. Nevertheless, the estimated for this study suggests the post-COVID scenario might also impact the private practice. Costs from this study were obtained from both public and private quotations. In addition, biosafety protocols do not differ between public and private practices. Based on that, scenarios discussed in this paper are relevant to both sectors. The economical impact for the adequacy of the changes presented in this study considers only 1 dental office that previously treated 8 patients per period in the pre-COVID and will now assist 4 in the post-COVID. For private clinics, there will be an increase in expenses and a lower financial return, in view of the reduction in the number of dental consultations. For public health services, there will be a reduction in resoluteness, being a challenge for managers to organize the new demand. 
Table 1. Description of the products and equipment, prices and sensibility analysis for the Dental Consultation, pre-COVID-19 scenario.

\begin{tabular}{|c|c|c|c|c|c|c|c|c|c|}
\hline Material & Use & $\begin{array}{l}\text { Quantity } \\
\text { per Day }\end{array}$ & $\begin{array}{c}\text { Number of } \\
\text { Uses }\end{array}$ & $\begin{array}{c}\text { Average } \\
\text { Price (R\$) }\end{array}$ & Quantity & $\begin{array}{l}\text { Net Price } \\
(\mathbf{R} \$)\end{array}$ & $\begin{array}{l}\text { Total Cost } \\
\quad(\mathbf{R} \$)\end{array}$ & $\begin{array}{l}\text { Minimum } \\
(-20 \%)(R \$)\end{array}$ & $\begin{array}{c}\text { Maximum } \\
(+20 \%)(\mathrm{R} \$)\end{array}$ \\
\hline Disposable Glove & PPE for Dentist and OHA & 64 & 1 & 13.79 & 100 un. & 0.14 & 8.83 & 7.06 & 10.59 \\
\hline Disposable Mask & PPE for Dentist and OHA & 4 & 1 & 6.00 & 100 un. & 0.06 & 0.24 & 0.19 & 0.29 \\
\hline Disposable Cap & PPE for Dentist and OHA & 4 & 1 & 10.00 & 100 un. & 0.10 & 0.40 & 0.32 & 0.48 \\
\hline Protective Goggles & PPE for Dentist and OHA & 2 & 4080 (Year) & 10.82 & 1 un. & 10.82 & 0.08 & 0.07 & 0.10 \\
\hline Plastic Film & Protect the Surfaces & $32 \mathrm{~m}$ & 16 & 25.4 & $300 \mathrm{~m}$ & 0.08 & 2.71 & 2.17 & 3.25 \\
\hline Liquid Soap & Clean Hands and Arms & $20 \mathrm{~mL}$ & 32 & 50.30 & $5 \mathrm{~L}$ & 0.01 & 0.20 & 0.16 & 0.24 \\
\hline Paper Tower & Drying Hands and Arms & 64 & 1 & 8.13 & 1000 un. & 0.01 & 0.52 & 0.42 & 0.62 \\
\hline Sodium Hypochlorite Solution & Clean Floors and Walls & $50 \mathrm{~mL}$ & 2 & 7.14 & $5 \mathrm{~L}$ & 0.001 & 0.07 & 0.057 & 0.09 \\
\hline $70 \%$ Alcohol & Clean the Dental Office & $30 \mathrm{~mL}$ & 16 & 55.91 & $5 \mathrm{~L}$ & 0.01 & 0.34 & 0.27 & 0.40 \\
\hline & & & & & \multicolumn{2}{|c|}{ Total per Day $(\mathrm{R} \$)$} & 13.39 & 10.71 & 16.07 \\
\hline & & & & & \multicolumn{2}{|c|}{ Total per Service Shift $(\mathrm{R} \$)$} & 6.69 & 5.36 & 8.03 \\
\hline & & & & & \multicolumn{2}{|c|}{ Total per Patient $(\mathrm{R} \$)$} & 0.84 & 0.67 & 1.00 \\
\hline & & & & & \multicolumn{2}{|c|}{ Total per Year $(\mathrm{R} \$)$} & $3,413.94$ & $2,731.16$ & $4,096.73$ \\
\hline
\end{tabular}

Table 2. Description of the products and equipment, prices and sensibility analysis for the Dental Consultation, post-COVID-19 scenario.

\begin{tabular}{|c|c|c|c|c|c|c|c|c|c|}
\hline Material & Use & $\begin{array}{l}\text { Quantity } \\
\text { per day }\end{array}$ & $\begin{array}{l}\text { Number of } \\
\text { Uses }\end{array}$ & $\begin{array}{c}\text { Average } \\
\text { Price }(\mathbf{R} \$)\end{array}$ & Quantity & $\begin{array}{l}\text { Net Price } \\
\qquad(\mathbf{R} \$)\end{array}$ & $\begin{array}{c}\text { Total cost } \\
\quad(\mathbf{R} \$)\end{array}$ & $\begin{array}{c}\text { Minimum } \\
(-20 \%)(\mathrm{R} \$)\end{array}$ & $\begin{array}{c}\text { Maximum } \\
(+20 \%)(\mathbf{R} \$)\end{array}$ \\
\hline Disposable Glove & PPE for Dentist and OHA & 32 & 1 & 41.96 & 100 un. & 0.42 & 13.43 & 10.74 & 16.11 \\
\hline Disposable Mask & PPE for Dentist and OHA & 8 & 1 & 205.67 & 50 un. & 4.11 & 32.91 & 26.33 & 39.49 \\
\hline Disposable Cap & PPE for Dentist and OHA & 8 & 1 & 24.32 & 100 un. & 0.24 & 1.95 & 1.56 & 2.33 \\
\hline Protective Goggles & PPE for Dentist and OHA & 4 & 2040 (Year) & 10.82 & 1 un. & 10.82 & 0.17 & 0.14 & 0.20 \\
\hline $\begin{array}{l}\text { Disposable Waterproof } \\
\text { Medical Coat } 30 \mathrm{~g}\end{array}$ & PPE for Dentist and OHA & 2 & 1 & 15.15 & 1 un. & 15.15 & 30.30 & 24.24 & 36.36 \\
\hline $\begin{array}{l}\text { Disposable N95 or } \\
\text { PFF2 Mask }\end{array}$ & PPE for Dentist and OHA & 2 & 4 & 290.27 & 20 un. & 14.51 & 3.63 & 2.90 & 4.35 \\
\hline Face Shield & PPE for Dentist and OHA & 4 & 2040 (Year) & 35.63 & 1 un. & 35.63 & 0.56 & 0.45 & 0.67 \\
\hline
\end{tabular}




\begin{tabular}{|c|c|c|c|c|c|c|c|c|c|}
\hline $\begin{array}{l}\text { Disposable Fenestrated } \\
\text { Surgical Drape }\end{array}$ & $\begin{array}{l}\text { Protection to the Face of } \\
\text { Patient }\end{array}$ & 1 & 1 & 3.78 & 1 un. & 3.78 & 30.24 & 24.19 & 36.29 \\
\hline Infrared Thermometer & Measuring of Temperature & 1 & 2040 (Year) & 282.90 & $1 \mathrm{un}$. & 282.90 & 1.11 & 0.89 & 1.33 \\
\hline Oximeter & $\begin{array}{l}\text { Measuring of Oxygen } \\
\text { Saturation }\end{array}$ & 1 & 2040 (Year) & 141.67 & $1 \mathrm{un}$. & 141.67 & 0.56 & 0.44 & 0.67 \\
\hline Disposable Shoe Cover & Foot Protection & 24 & 1 & 39.76 & 100 un. & 0.40 & 9.54 & 7.63 & 11.45 \\
\hline Plastic Film & Protect the Surfaces & $16 \mathrm{~m}$ & 8 & 25.40 & $300 \mathrm{~m}$ & 0.08 & 1.35 & 1.08 & 1.63 \\
\hline Liquid Soap & Clean Hands and Arms & $20 \mathrm{~mL}$ & 16 & 50.30 & $5 \mathrm{~L}$ & 0.01 & 0.20 & 0.16 & 0.24 \\
\hline Paper Tower & Drying Hands and Arms & 32 & 1 & 8.13 & 1000 un. & 0.01 & 0.26 & 0.21 & 0.31 \\
\hline Alcohol 70\% & Clean Floors and Walls & $50 \mathrm{~mL}$ & 8 & 55.91 & $5 \mathrm{~L}$ & 0.01 & 0.56 & 0.45 & 0.67 \\
\hline Sanitizing Carpet & Clean the Foots & 1 & 2040 (Year) & 66.27 & $60 \times 40 \mathrm{~cm}$ & 66.27 & 0.26 & 0.21 & 0.31 \\
\hline Saline Solution & $\begin{array}{l}\text { Clean the Nasal Cavity of } \\
\text { Dentist and OHA }\end{array}$ & $20 \mathrm{~mL}$ & 4 & 91.47 & $12 \mathrm{~L}$ & 0.01 & 0.15 & 0.12 & 0.18 \\
\hline Chlorhexidine solution & $\begin{array}{l}\text { Clean Neck of Dentist and } \\
\text { OHA }\end{array}$ & $40 \mathrm{~mL}$ & 8 & 20.68 & $1 \mathrm{~L}$ & 0.02 & 0.83 & 0.66 & 0.99 \\
\hline $\begin{array}{l}\text { Sodium Hypochlorite } \\
\text { solution }\end{array}$ & Clean the Dental Office & $50 \mathrm{~mL}$ & 2 & 7.14 & $5 \mathrm{~L}$ & 0.001 & 0.07 & 0.06 & 0.09 \\
\hline & & & & \multicolumn{3}{|c|}{ Total per Day $(\mathrm{R} \$)$} & 128.07 & 102.46 & 153.68 \\
\hline & & & & \multicolumn{3}{|c|}{ Total per Service Shift $(\mathrm{R} \$)$} & 64.04 & 51.23 & 76.84 \\
\hline & & & & \multicolumn{3}{|c|}{ Total per Patient $(\mathrm{R} \$)$} & 16.01 & 12.81 & 19.21 \\
\hline & & & & \multicolumn{3}{|c|}{ Total per Year $(\mathrm{R} \$)$} & $32,657.96$ & $26,126.37$ & $39,189.56$ \\
\hline
\end{tabular}


Within the private practice, the costs are often transferred to the patient, which deserves to be informed about the efforts necessary to achieve efficiency under "new normal” biosafety routine. In Brazil, a public and universal health system also include oral healthcare [21]. Nowadays, there is evidence of around 25 thousand dental offices in primary care and an estimated number of 58 thousand dentists within the public healthcare sector [21]. The large number of healthcare centers and professionals within the public sector can imply in a huge economic investment, considering the post-COVID scenario. Seems reasonable that many cities are likely to close their oral healthcare services if there is no further support and increase of incentives from the federal government.

Therefore, results from this study may impact significantly the budget of public health system in Brazil. Apart from the emergency of acquiring PPE for health-workers that fight COVID-19 directly, the public health system is expected to deal the increased price of PPE. In addition, the new biosafety recommendations imply the need of acquiring more quantity and new type of PPE. Some of the recommendations of the post-COVID scenario may also become permanent, in example of the use of face shield and use of $\mathrm{N} 95 / \mathrm{FFP}_{2}$ mask for aerosol generating procedures. Future investigations should consider the estimation of costs once pandemic has ended and the "new normal" recommendations can be defined. This study may therefore contribute to policy makers and healthcare managers for driven a more efficient and reasonable allocation of economic resources.

This study has limitations with regards to low comparability to other countries, since prices collected for this study reproduces the economic scenario in Brazil. It is possible that prices vary according to market availability, purchase demand and taxes fluctuation. To mitigate biased analysis due to price variation, we performed a sensitivity analysis. Even though, results have shown that direct costs of post-COVID scenario are still very high compared to pre-COVID scenario, even considering the most optimistic price variation.

Future investigations might evaluate evidence on how increasing direct costs during post-COVID scenario contributed to limit population access to oral healthcare. This study suggests that regular oral healthcare assistance during COVID-19 pandemic can become prohibitive to public health sector. Ensuring access to only urgency and emergency cases is transitory, being necessary to economically plan the resume of elective procedures in dentistry.

\section{Conclusion}

New biosafety recommendations increased significantly the costs of oral healthcare assistance during COVID-19 pandemic. Decision making of healthcare managers must consider rational and equity allocation of financial resources.

\section{Authors' Contributions}

YWC (iD) 0000-0002-3570-9904 Conceptualization, Methodology, Writing - Original Draft Preparation, Writing Review and Editing and Project administration.

ROS (D) OOOO-0001-8413-8071 Investigation, Formal Analysis, Data Curation and Writing - Original Draft Preparation.

LFF (D) 0000-0002-4948-4347 Investigation, Formal Analysis, Data Curation and Writing - Original Draft Preparation.

EHGL (D) 0000-0003-3431-115X Conceptualization, Methodology, Formal Analysis and Writing - Review and Editing.

AMBS (D) 0000-0002-6575-2209 Investigation, Formal Analysis, Data Curation and Writing - Original Draft Preparation.

DFBC (iD 0000-0002-9166-0367 Methodology, Investigation, Formal Analysis, Writing - Original Draft Preparation.

MCM (D) 0000-0003-2673-3627 Conceptualization, Methodology, Formal Analysis and Writing - Review and Editing. 
ACP (D) 0000-0003-1703-8171 Conceptualization, Methodology, Formal Analysis and Writing - Review and Editing. All authors declare that they contributed to critical review of intellectual content and approval of the final version to be published.

\section{Financial Support}

None.

\section{Conflict of Interest}

The authors declare no conflicts of interest.

\section{References}

[1] Zhu N, Zhang D, Wang W, Li X, Yang B, Song J, et al. A novel coronavirus from patients with pneumonia in China, 2019. N Engl J Med 2020; 382(8):727-33. https://doi.org/10.1056/NEJMoa2001017

[2] Cohen J, Normile D. New SARS-like virus in China triggers alarm. Science 2020; 367(6475):234-5. https://doi.org/10.1126/science.367.6475.234

[3] World Health Organization. WHO Director-General's opening remarks at the media briefing on COVID-19 - 11 March 2020. Available from: https://www.who.int/dg/speeches/detail/who-director-general-s-opening-remarks-atthe-media-briefing-on-covid-19---11-march-2020. [Accessed on June 14, 2020].

[4] Zhang Y, Xu J, Li H, Cao B. A novel coronavirus (COVID-19) outbreak: a call for action. Chest 2020; 157(4):e99e101. https://doi.org/10.1016/j.chest.2020.02.014

[5] Arango C. Lessons learned from the coronavirus health crisis in Madrid, Spain: How COVID-19 has changed our lives in the last 2 weeks. Biol Psychiatry 2020; 2020:So006-3223(20)31493-1. https://doi.org/10.1016/j.biopsych.2020.04.003

[6] Johns Hopkins University. JHU COVID-19 Resource Center. COVID-19 Dashboard by the Center for Systems Science and Engineering (CSSE) at Johns Hopkins University (JHU). Avaliable from: https://coronavirus.jhu.edu/map.html. [Accessed on June 14, 2020].

[7] Wilder-Smith A, Freedman DO. Isolation, quarantine, social distancing and community containment: pivotal role for old-style public health measures in the novel coronavirus (2019-nCoV) outbreak. J Travel Med 2020; 27(2):taaa020. https://doi.org/10.1093/jtm/taaa020

[8] Kowalski LP, Sanabria A, Ridge JA, Ng WT, de Bree R, Rinaldo A, et al. COVID-19 pandemic: effects and evidencebased recommendations for otolaryngology and head and neck surgery practice. Head Neck 2020; 42(6):1259-67. https://doi.org/10.1002/hed.26164

[9] Thamboo A, Lea J, Sommer DD, Sowerby L, Abdalkhani A, Diamond C, et al. Clinical evidence based review and recommendations of aerosol generating medical procedures in otolaryngology - head and neck surgery during the COVID-19 pandemic. J Otolaryngol Head Neck Surg 2020; 49(1):28. https://doi.org/10.1 186/s40463-020-00425-6

[10] Peres MA, Macpherson LMD, Weyant RJ, Daly B, Venturelli R, Mathur MR, et al. Oral diseases: a global public health challenge. Lancet 2019; 394(10194):249-60. https://doi.org/10.1016/So140-6736(19)31146-8

[11] Hammel JM, Fischel J. Dental emergencies. Emerg Med Clin North Am 2019; 37(1):81-93. https://doi.org/10.1016/j.emc.2018.09.008

[12] Carrer FCA, Galante ML, Gabriel M, Pischel N, Giraldes AI, Neumann A, et al. A COVID-19 na América Latina e suas repercussões para a odontologia. Rev Panam Salud Publica 2020; 44:e66. https://doi.org/10.26633/RPSP.2020.66 [In Portuguese]

[13] Meng L, Hua F, Bian Z. Coronavirus disease 2019 (COVID-19): emerging and future challenges for dental and oral medicine. J Dent Res 2020; 99(5):481-7. https://doi.org/10.1177/0022034520914246

[14] Bescos R, Casas-Agustench P, Belfield L, Brookes Z, Gabaldón T. Coronavirus Disease 2019 (COVID-19): emerging and future challenges for dental and oral medicine. J Dent Res 2020; 22034520932149. https://doi.org/10.1177/0022034520932149

[15] Canby JB 4th. Applying activity-based costing to healthcare settings. Healthc Financ Manage 1995; 49(2):50-6.

[16] Husereau D, Drummond M, Petrou S, Carswell C, Moher D, Greenberg D, et al. Consolidated Health Economic Evaluation Reporting Standards (CHEERS) - explanation and elaboration: a report of the ISPOR Health Economic Evaluation Publication Guidelines Good Reporting Practices Task Force. Value Health 2013; 16(2):231-50. https://doi.org/10.1016/j.jval.2013.02.002

[17] Brasil. Ministério da Saúde. Secretaria de Ciência, Tecnologia e Insumos Estratégicos. Departamento de Ciência e Tecnologia. Diretrizes Metodológicas: Análise de Impacto Orçamentário: Manual para o Sistema de Saúde do Brasil. Brasília: Ministério da $\quad$ Saúde, 2012 Available from: 
http://bvsms.saude.gov.br/bvs/publicacoes/diretrizes_metodologicas_diretriz_avaliacao_economica.pdf. [Accessed on June 14, 2020]. [In Portuguese]

[18] Drummond MF, Sculpher MJ, Claxton K, Stoddart GL, Torrance GW. Methods for the Economic Evaluation of Health Care Programmes. 4. ed. Oxford: Oxford University Press; 2015.

[19] Brasil. Agência Nacional de Vigilância Sanitária (ANVISA). Nota Técnica GVIMS/GGTES/ANVISA No 04/2020. Orientações para serviços de saúde: Medidas de prevenção e controle que devem ser adotadas durante a assistência aos casos suspeitos ou confirmados de infecção pelo novo coronavírus (SARS-CoV-2) - 08.05.2020. Brasília: ANVISA, 2020. Available from: http://portal.anvisa.gov.br/documents/33852/271858/Nota+T\%C3\%A9cnica+n+042020+GVIMS-GGTES-ANVISA/ab598660-3de4-4f14-8e6f-b9341c196b28. Accessed on June 14, 2020]. [In Portuguese]

[20] Zeegen EN, Yates AJ, Jevsevar DS. After the COVID-19 pandemic: returning to normalcy or returning to a new normal? J Arthroplasty 2020; So883-5403(20)30427-7. https://doi.org/10.1016/j.arth.2020.04.040

[21] Gabriel M, Cayetano MH, Chagas MM, Araujo ME, Dussault G, Pucca Junior GA, et al. Admission of dentist in Brazilian Universal Health System (SUS): a priority agenda for the strengthening of Smiling Brazil. Cien Saude Coletiva 2020; 25(3):859-68. https://doi.org/10.1590/1413-81232020253.14532018 